Acta Crystallographica Section C

Crystal Structure

Communications

ISSN 0108-2701

\section{Acidic and anionic forms of 1,3-cyclic dihydroxyacetone phosphate (cDHAP) dimethyl acetal}

\section{Katarzyna Ślepokura* and Irmina Mitaszewska}

Faculty of Chemistry, University of Wrocław, 14 F. Joliot-Curie Street, 50-383

Wrocław, Poland

Correspondence e-mail: slep@eto.wchuwr.pl

Received 3 February 2011

Accepted 29 March 2011

Online 13 April 2011

The six-membered cyclic phosphate diester, 5,5-dimethoxy-2hydroxy-1,3,2-dioxaphosphorinan-2-one, $\mathrm{C}_{5} \mathrm{H}_{11} \mathrm{O}_{6} \mathrm{P}$ or $(\mathrm{MeO})_{2^{-}}$ cDHAP, which is the dimethyl acetal of cyclic dihydroxyacetone phosphate (cDHAP), has been obtained in the form of two new cyclohexylammonium (cha) salts, cyclohexylammonium 5,5-dimethoxy-2-oxo-1,3,2-dioxaphosphorinan-2-olate monohydrate, (cha) $\left[(\mathrm{MeO})_{2} \mathrm{cDHAP}\right] \cdot \mathrm{H}_{2} \mathrm{O}$ or $\mathrm{C}_{6} \mathrm{H}_{14} \mathrm{~N}^{+}$.$\mathrm{C}_{5} \mathrm{H}_{10} \mathrm{O}_{6} \mathrm{P}^{-} \cdot \mathrm{H}_{2} \mathrm{O}$, and cyclohexylammonium 5,5-dimethoxy-2oxo-1,3,2-dioxaphosphorinan-2-olate, (cha) [( $\left.\mathrm{MeO})_{2} \mathrm{cDHAP}\right]$ or $\mathrm{C}_{6} \mathrm{H}_{14} \mathrm{~N}^{+} \cdot \mathrm{C}_{5} \mathrm{H}_{10} \mathrm{O}_{6} \mathrm{P}^{-}$, as well as in the form of the anhydrous free acid, $(\mathrm{MeO})_{2} \mathrm{cDHAP}$. It is shown that protonation of the cyclic phosphate group influences the chair conformation of the $\mathrm{P} / \mathrm{O} / \mathrm{C} / \mathrm{C} / \mathrm{C} / \mathrm{O}$ 1,3,2-dioxaphosphorinane ring, and that differences in the ring conformation correlate with different deformations observed in the ionized and protonated phosphate groups. The ring is more evenly puckered in the anions, in contrast with the flattening observed in the structure of the free acid.

\section{Comment}

Six-membered cyclic phosphate esters are constituents of a number of biologically important molecules, such as $3^{\prime}: 5^{\prime}$ cyclic nucleotides, e.g. cAMP. Dihydroxyacetone phosphate (DHAP), the linear form of cDHAP, is one of the most important biochemical intermediates and of great importance for all living cells [for a review, see Ślepokura \& Lis (2010)]. The cyclic form, cDHAP, has aroused interest recently as a new molecule of biological importance (Goswami \& Adak, 2002). Occurring in living organisms, small cyclic phosphates of cDHAP-like structure began to attract attention when their biological activity as signalling molecules was suggested (Shinitzky et al., 2000). Cyclic glycerophosphates can be formed by enzymatic degradation of phospholipids, e.g. 1,3cyclic glycerophosphate is naturally formed by the action of phospholipase $\mathrm{C}$ on phosphatidyl glycerol.

Only five of more than 160 hits for cyclic phosphates with six-membered rings deposited in the Cambridge Structural
Database (CSD, Version 5.32; Allen, 2002) bear the $\mathrm{H}$ atom at the exocyclic $\mathrm{O}$ atom. We will discuss just three of the reported protonated cyclic phosphates [CSD refcodes ETPHOS (Gerlt et al., 1980), KADPUA (Johnson et al., 1989) and SEZRUL (Samas et al., 2007)], because the remaining two have high $R$ factors and low bond precision, and the positions of the $\mathrm{H}$ atoms were not determined.

Previously, we have reported the synthesis and structural investigations of nine different salts of $(\mathrm{MeO})_{2} \mathrm{cDHAP}$ with both organic and inorganic cations $\left[(5 a)-(5 e)\right.$ and $\left(5 e^{\prime}\right)-(5 h)$; Ślepokura, 2008], along with its phenyl derivative, $(\mathrm{MeO})_{2} \mathrm{cDHAP}(\mathrm{Ph})$ [(4); Ślepokura \& Lis, 2004b]. Among these, the structures of two cyclohexylammonium (cha) salts and the acid in the form of an oxonium salt were presented: (cha) $\left[(\mathrm{MeO})_{2} \mathrm{cDHAP}\right] \cdot 3 \mathrm{H}_{2} \mathrm{O}, \quad(5 a)$, (cha) $\left[(\mathrm{MeO})_{2} \mathrm{cDHAP}\right] \cdot-$ $\mathrm{H}_{2} \mathrm{O},(5 b)$, and $\left(\mathrm{H}_{5} \mathrm{O}_{2}\right)\left[(\mathrm{MeO})_{2} \mathrm{cDHAP}\right],(5 c)$.

The present paper concerns the synthesis and crystal structure of 5,5-dimethoxy-2-hydroxy-1,3,2-dioxaphosphorinan-2-one, the dimethyl acetal of cyclic dihydroxyacetone phosphate, $(\mathrm{MeO})_{2} \mathrm{cDHAP}$, in the form of two crystalline cha salts, (cha) $\left[(\mathrm{MeO})_{2} \mathrm{cDHAP}\right] \cdot \mathrm{H}_{2} \mathrm{O},(5 i)$ [polymorphous form of $(5 b)]$, and anhydrous (cha) [(MeO) $\left.)_{2} \mathrm{cDHAP}\right],(5 j)$, as well as in the form of the free acid, $(\mathrm{MeO})_{2} \mathrm{cDHAP},(5 k)$.

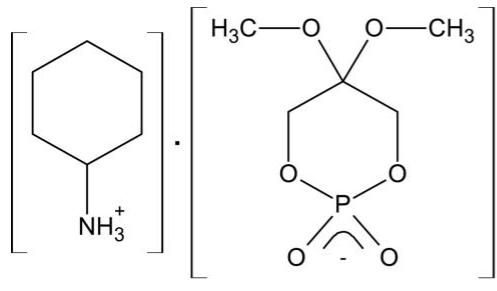

(5i) monohydrate

$(5 j)$ anhydrous

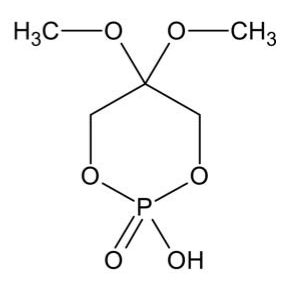

$(5 k)$
The overall structures of the $(\mathrm{MeO})_{2} \mathrm{cDHAP}$ anions in compounds $(5 i)$ and $(5 j)$ bear great similarities with each other and with the previously reported anions in $(5 a)-(5 h)$ (Ślepokura, 2008). The six-membered 1,3,2-dioxaphosphorinane ring adopts a chair $(C)$ conformation only slightly distorted towards an envelope $(E)$, which is reflected in the values of the dihedral angles between the least-squares plane through the four central atoms of the ring $(\mathrm{O} 1 / \mathrm{O} 3 / \mathrm{C} 1 / \mathrm{C} 3)$ and the $\mathrm{O} 1 / \mathrm{P} /$ $\mathrm{O} 3$ and $\mathrm{C} 1 / \mathrm{C} 2 / \mathrm{C} 3$ planes $\left(\varphi_{1}\right.$ and $\left.\varphi_{2}\right)$, as well as in the CremerPople puckering parameters (Cremer \& Pople, 1975; see Table 1). The values of $\left|\varphi_{2}-\varphi_{1}\right|$ for $(5 a),(5 b),(5 i)$ and $(5 j)$ clearly show that the flattening of the dioxaphosphorinane ring at the $\mathrm{P}$ atom is negligible in the $(\mathrm{MeO})_{2} \mathrm{CDHAP}$ anions and that the conformation of the rings is close to an ideal chair.

Selected geometric parameters for $(5 i)-(5 k)$ are given in Table 2. The deformation of the phosphate group from the ideal tetrahedral shape, which was observed previously in $(5 a)-(5 h)$, is also observed in $(5 i)$ and $(5 j)$. The deformation of the ionized cyclic phosphate is seen particularly in the endocyclic $\mathrm{O} 1-\mathrm{P} 1-\mathrm{O} 3$ and exocyclic $\mathrm{O} 4-\mathrm{P} 1-\mathrm{O} 5$ bond angles, which are, respectively, the smallest $\left[101.73(11)^{\circ}\right.$ on average 


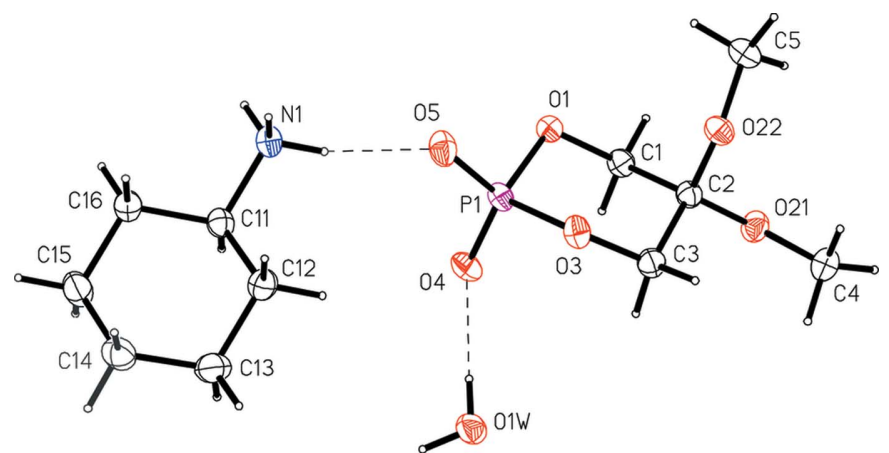

(5i)

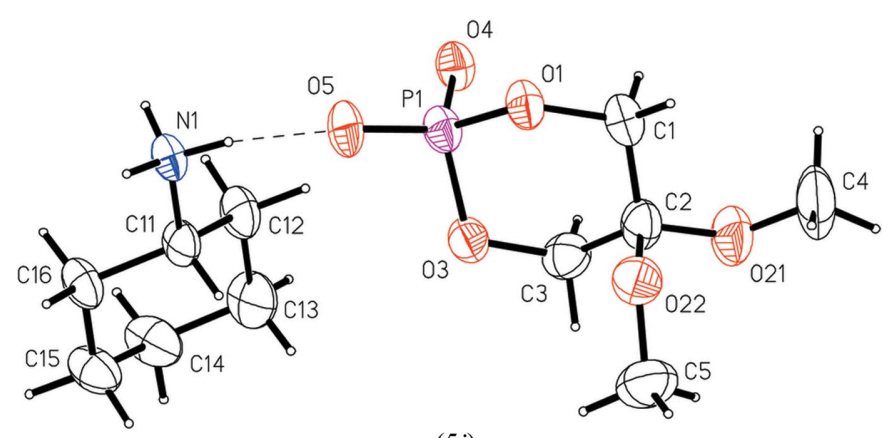

$(5 j)$

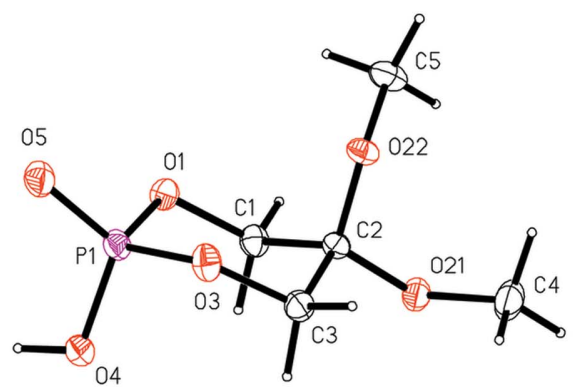

$(5 k)$

Figure 1

Views of (5i) (top), (5j) (middle) and (5k) (bottom), showing the atomnumbering schemes and the symmetry-independent $\mathrm{N}^{+}-\mathrm{H} \cdots \mathrm{O}^{-}$and $\mathrm{O}-\mathrm{H} \cdots \mathrm{O}^{-}$hydrogen bonds (dashed lines). Displacement ellipsoids are drawn at the $50 \%$ probability level.

for $(5 a)-(5 j)]$ and the largest $\left[119.24(12)^{\circ}\right.$ on average]. The values of the endo- and exocyclic $\mathrm{O}-\mathrm{P}-\mathrm{O}$ angles correlate with the respective $\mathrm{P}-\mathrm{O}$ bond lengths. In all the known $(\mathrm{MeO})_{2} \mathrm{cDHAP}$ anions, the $\mathrm{P}-\mathrm{O}_{\text {endo }}$ bonds are all approximately $1.60 \AA$ and more than $0.1 \AA$ longer than the $\mathrm{P}-\mathrm{O}_{\text {exo }}$ bonds.

A completely different deformation is present in the protonated phosphate group of the $(\mathrm{MeO})_{2} \mathrm{CDHAP}$ molecule in $(5 k)$. The hydroxy group in $(5 k)$ adopts an axial position similar to the previously reported structures ETPHOS, KADPUA and SEZRUL. As can be seen by the $\mathrm{P}-\mathrm{O}_{\text {endo, }}$, $\mathrm{P}-\mathrm{O}(\mathrm{H})$ and $\mathrm{P}=\mathrm{O}$ distances (Table 2), the protonation of the phosphate group affects to a larger extent the length of the $\mathrm{P}-\mathrm{O}_{\text {endo }}$ bonds (becoming, on average, $0.03 \AA$ shorter than in the anion) than that of the exocyclic equatorially oriented $\mathrm{P} 1=\mathrm{O} 5$ bond [becoming formally double, but only slightly shortened compared with the $\mathrm{P}-\mathrm{O}_{\text {exo }}$ bonds in the

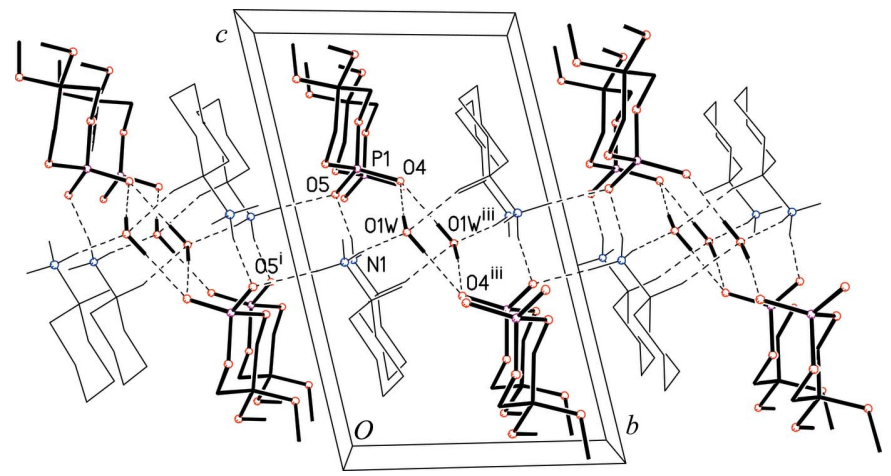

Figure 2

The double layer parallel to the (001) plane in (5i), built up from $(\mathrm{MeO})_{2} \mathrm{cDHAP}$ anions (solid lines), cha cations (thin lines) and water molecules joined by $\mathrm{N}-\mathrm{H} \cdots \mathrm{O}$ and $\mathrm{O}-\mathrm{H} \cdots \mathrm{O}$ hydrogen bonds and $\mathrm{C}-$ $\mathrm{H} \cdots \mathrm{O}$ contacts (dashed lines). $\mathrm{H}$ atoms not involved in hydrogen bonding have been omitted for clarity. [Symmetry codes: (i) $-x,-y$, $-z+1$; (iii) $-x+1,-y+1,-z+1$.]

$(\mathrm{MeO})_{2} \mathrm{cDHAP}$ anions]. Within the $\mathrm{O}-\mathrm{P}-\mathrm{O}$ angles in $(5 k)$, the exocyclic $\mathrm{O} 4-\mathrm{P} 1-\mathrm{O} 5$ angle is the largest $\left[115.13(6)^{\circ}\right]$, although none of them is distinctly smaller than the others. Instead, in the protonated phosphate group, three lower values for the angles involving endocyclic $\mathrm{O}$ atoms and three higher values for the angles involving $\mathrm{P}=\mathrm{O}$ bonds are observed. It may be noted that the geometry of the phosphate group in $(5 k)$ is similar to that observed in the phenyl derivative, (4). These differences in the deformations observed in the ionized and protonated phosphate groups are accompanied by different distortions of the $\mathrm{P} / \mathrm{O} / \mathrm{C} / \mathrm{C} / \mathrm{C} / \mathrm{O}$ rings. In contrast with the almost ideal chair conformation in the $(\mathrm{MeO})_{2} \mathrm{cDHAP}$ anions of $(5 a)-(5 j)$, the ring in acidic $(5 k)$ is significantly flattened at the $\mathrm{P}$ atom (see Table 1 ), which is comparable with the conformations observed in phenyl derivative (4) and the acidic cyclic phosphates ETPHOS and SEZRUL.

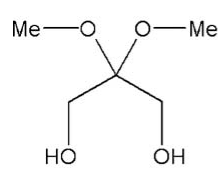

$(\mathrm{MeO})_{2} \mathrm{DHA}(3)$

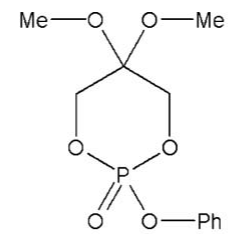

$(\mathrm{MeO})_{2} \mathrm{cDHAP}(\mathrm{Ph})(4)$<smiles>COC(CO)(COP(=O)(O)OC)O[Na]</smiles>

(MeO) ${ }_{2} \mathrm{DHAP}(6)$ $(\mathrm{MeO})_{2} \mathrm{DHAP}(\mathrm{Ph})(6 e)$
It has been shown that the acetal group in the analogous linear compounds, different salts of $(\mathrm{MeO})_{2} \mathrm{DHAP}$ and $(\mathrm{MeO})_{2} \mathrm{DHAP}(\mathrm{Ph})[(6 a)-(6 e)$; Ślepokura \& Lis, 2006], and in the unphosphorylated species $(\mathrm{MeO})_{2} \mathrm{DHA}[(3)$; Ślepokura \& Lis, 2004a] seems to be very rigid, and its conformation is independent of phosphorylation, the ionization state of the inserted phosphate group, or additional substitution. It is likely that such a conformation is determined and stabilized by the generalized anomeric effect. The acetal group in the cyclic compounds $(5 i)-(5 k)$, as in (4) and $(5 a)-(5 h)$, reveals some 

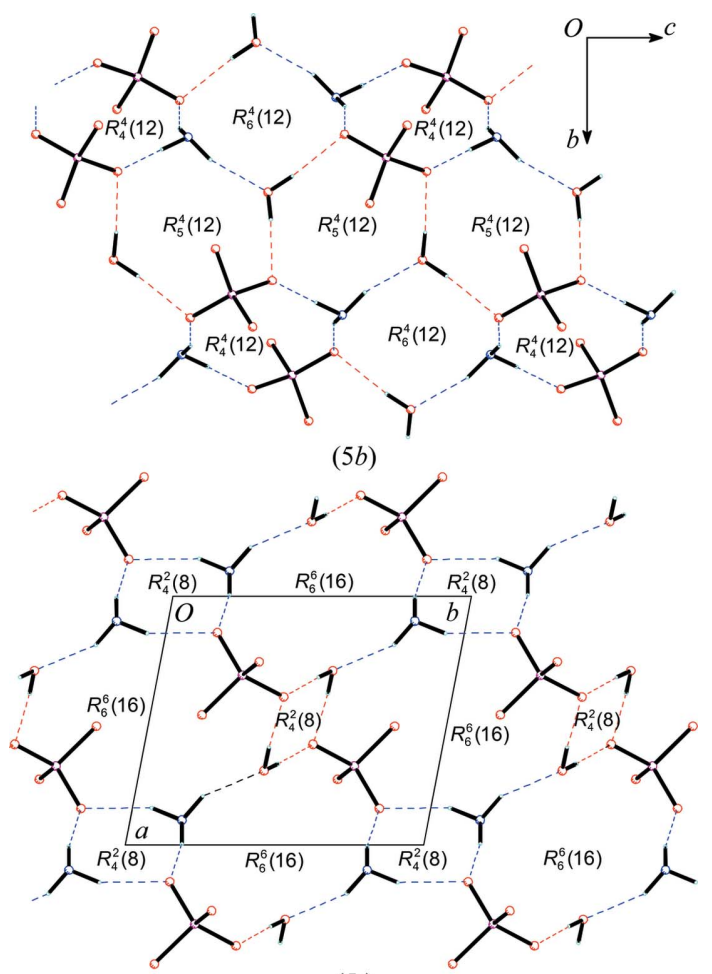

(5i)

Figure 3

A comparison of the layer constructions observed in two polymorphous forms of (cha) $\left[(\mathrm{MeO})_{2} \mathrm{cDHAP}\right] \cdot \mathrm{H}_{2} \mathrm{O}$, viz. monoclinic (5b) (top; Slepokura, 2008) and triclinic (5i) (bottom; this work). Phosphate and ammonium groups represent the anions and cations, respectively. $\mathrm{N}^{+}-$ $\mathrm{H} \cdots \mathrm{O}^{-} / \mathrm{OW}$ and $\mathrm{OW}-\mathrm{H} \cdots \mathrm{O}^{-}$hydrogen bonds are shown as dashed lines (blue and red, respectively, in the electronic version of the paper).

common features with linear (3) and $(6 a)-(6 e)$ (see scheme above): the relevant $\mathrm{C} 4-\mathrm{O} 21-\mathrm{C} 2-\mathrm{O} 22$ and $\mathrm{C} 5-\mathrm{O} 22-$ $\mathrm{C} 2-\mathrm{O} 21$ torsion angles show a synclinal orientation of the methyl groups ( $\mathrm{C} 4$ and $\mathrm{C} 5)$ in relation to the acetal atoms $\mathrm{O} 22$ and O21. Similarly, as was observed in the structures of (3), (4), (5a)-(5h) and $(6 a)-(6 e)$, two of the angles with their vertex on acetal atom $\mathrm{C} 2$ are much smaller than the others (Table 2).

The cations and anions in $(5 i)$ and $(5 j)$ are arranged in a way that leads to the aggregation of their hydrophilic and hydrophobic groups into distinct regions in the crystals. The packing schemes of $(5 i)$ and $(5 j)$ are dominated by $\mathrm{N}^{+}-\mathrm{H} \cdots \mathrm{O}^{-}$ hydrogen bonds, but in the hydrated salt $(5 i)$, as in $(5 a)$ and (5b) (Ślepokura, 2008), an additional important role is played by contacts of the $\mathrm{N}^{+}-\mathrm{H} \cdots \mathrm{OW}$ and $\mathrm{OW}-\mathrm{H} \cdots \mathrm{O}^{-}$type $(\mathrm{OW}$ is the water $\mathrm{O}$ atom). Geometric parameters of hydrogen bonds and close contacts are given in Table 3 .

The crystal structure of the monohydrated salt $(5 i)$ has a layered architecture (Fig. 2), similar to that observed in the other hydrated cha salts, $(5 a)$ and $(5 b)$. Each cha cation is directly linked by two charge-assisted $\mathrm{N}-\mathrm{H} \cdots \mathrm{O}$ hydrogen bonds to two adjacent $(\mathrm{MeO})_{2} \mathrm{cDHAP}$ anions, resulting in centrosymmetric $R_{4}^{2}(8)$ motifs (Fig. 3) [see Bernstein et al. (1995) for graph-set notation]. The same cation is linked to two additional anions via water-mediated hydrogen bonds. Thus, another type of ring is formed, $R_{6}^{6}(16)$, this time also

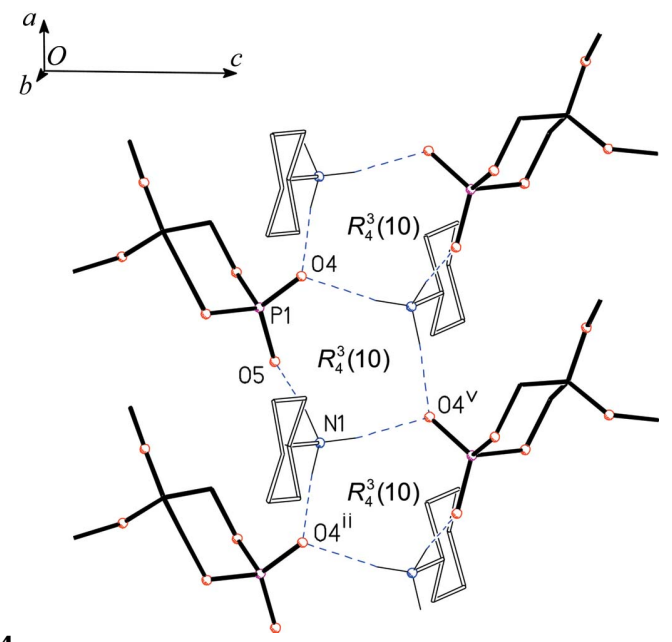

Figure 4

The polymeric ribbons with ladder-type hydrogen bonding formed in $(5 j)$ by the $(\mathrm{MeO})_{2} \mathrm{cDHAP}$ anions (solid lines) and cha cations (open lines) along the $a$ axis. $\mathrm{N}^{+}-\mathrm{H} \cdots \mathrm{O}^{-}$hydrogen bonds are shown as dashed lines. $\mathrm{H}$ atoms not involved in hydrogen bonding have been omitted for clarity. [Symmetry codes: (ii) $x-1, y, z$; (v) $x-\frac{1}{2},-y+\frac{1}{2},-z+1$.]

involving water molecules in addition to cha cations and $(\mathrm{MeO})_{2} \mathrm{cDHAP}$ anions. Another $R_{4}^{2}(8)$ ring results from the centrosymmetric $\mathrm{OW}-\mathrm{H} \cdots \mathrm{O}^{-}$bonds between two water molecules and two anions. The sequence of these three rings generates double layers parallel to the (001) plane, as shown in Figs. 2 and 3. The same types of interaction, namely cation $\cdots$ anion, cation $\cdots \mathrm{H}_{2} \mathrm{O} \cdots$ anion and anion $\cdots \mathrm{H}_{2} \mathrm{O} \cdots$ anion, were also observed in the polymorphous salt $(5 b)$. However, as shown in Fig. 3, the construction of the layers observed in $(5 b)$ is different: three unique rings generate the layer, $R_{4}^{4}(12)$ involving two cations and two anions, $R_{5}^{4}(12)$ involving one cation, two anions and two water molecules, and $R_{6}^{4}(12)$ involving two cations, two anions and two water molecules.

The arrangement of organic ions in the crystal structure of the anhydrous salt $(5 j)$ is different. Each cha cation is linked directly by three $\mathrm{N}^{+}-\mathrm{H} \cdots \mathrm{O}^{-}$hydrogen bonds to three adjacent $(\mathrm{MeO})_{2} \mathrm{cDHAP}$ anions. These interactions generate $R_{4}^{3}(10)$ rings forming ribbons with ladder-type hydrogen bonding along the $a$ axis, as shown in Fig. 4.

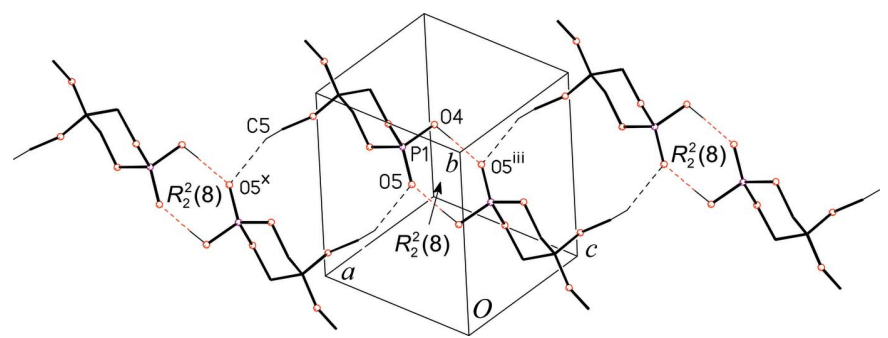

Figure 5

The ribbons in $(5 k)$ resulting from centrosymmetric molecular dimers [with $R_{2}^{2}(8)$ rings formed by the $(\mathrm{MeO})_{2} \mathrm{cDHAP}$ molecules joined via strong $\mathrm{O}-\mathrm{H} \cdots \mathrm{O}$ hydrogen bonds; dashed lines (red in the electronic version of the paper)] linked through $\mathrm{C}-\mathrm{H} \cdots \mathrm{O}$ contacts (black dashed lines). $\mathrm{H}$ atoms not involved in hydrogen bonding have been omitted for clarity. [Symmetry codes: (iii) $-x+1,-y+1,-z+1$; (x) $-x+2,-y+1$, $-z$.] 
The crystal packing of $(5 k)$ is determined by the strong centrosymmetric almost linear $\mathrm{O}-\mathrm{H} \cdots \mathrm{O}$ hydrogen bonds formed by the phosphate groups of two adjacent $(\mathrm{MeO})_{2^{-}}$ cDHAP molecules. In this way, centrosymmetric molecular dimers are formed (Fig. 5), giving rise to $R_{2}^{2}(8)$ rings. Adjacent dimers interact with each other via weak $\mathrm{C}-\mathrm{H} \cdots \mathrm{O}$ contacts, as shown in Fig. 5, resulting in ribbons along [101] $]$.

In conclusion, we have shown that protonation of the cyclic phosphate group influences the conformation of the 1,3,2dioxaphosphorinane ring, causing its flattening, i.e. deformation from the ideal chair towards an envelope. In other words, the ring is more evenly puckered in compounds with an ionized phosphate group than in the acid molecule. We have also demonstrated that differences in the ring conformation correlate with different deformations observed in the ionized and protonated phosphate groups. Some common features for analogous protonated and esterified compounds have been revealed. In addition, we have shown that the arrangement of the ions in the crystal structures of four different (cha)$\left[(\mathrm{MeO})_{2} \mathrm{cDHAP}\right]$ salts results in different crystal architectures, depending on water content, and gives rise to layers in hydrated $(5 a),(5 b)$ and $(5 i)$ and to ribbons in anhydrous $(5 j)$.

\section{Experimental}

The cyclohexylammonium salt of $(\mathrm{MeO})_{2}$ cDHAP was obtained by isolation of an intermediate in the basic hydrolysis of the cyclic triester derivative, using a method described previously (Ślepokura, 2008). Excess cyclohexylamine was removed by washing the crude product with diethyl ether. Concentration of the resulting mixture under vacuum and then under a nitrogen stream at room temperature gave two kinds of crystals, viz. small plates of $(5 j)$ and needles of the monohydrated monoclinic form described previously, $(5 b)$. Recrystallization of $(5 b)$ from water at room temperature resulted in large plates of its triclinic form, $(5 i)$.

Crystals of $(\mathrm{MeO})_{2} \mathrm{cDHAP},(5 k)$, were grown from an acidic solution prepared as follows. The cyclohexylammonium salt of $(\mathrm{MeO})_{2} \mathrm{cDHAP}$ (250 mg dissolved in a minimum quantity of water) was passed through an ion-exchange column (Dowex $50-\mathrm{H}^{+}$). The acidic solution was stirred at $313 \mathrm{~K}$ for $3.5 \mathrm{~h}$. Subsequent evaporation of the solvent under a nitrogen stream yielded large blocks of $(5 k)$.

\section{Table 1}

Values of $\varphi_{1}$ and $\varphi_{2}$, and the Cremer-Pople puckering parameters $Q, \theta$ and $\varphi$ for the $\mathrm{P} / \mathrm{O} 1 / \mathrm{C} 1 / \mathrm{C} 2 / \mathrm{C} 3 / \mathrm{O} 3$ rings in the $(\mathrm{MeO})_{2} \mathrm{cDHAP}$ anions in $(5 i)$ and $(5 j)$ and in the molecule of $(5 k)$, along with the relevant values for the previously reported compounds (4), (5a) and $(5 b)$.

\begin{tabular}{lcccccc}
\hline Compound & $\varphi_{1}\left(^{\circ}\right)$ & $\varphi_{2}\left(^{\circ}\right)$ & \multicolumn{1}{c}{$\left|\varphi_{2}-\varphi_{1}\right|\left(^{\circ}\right)$} & $Q(\AA)$ & $\theta\left(^{\circ}\right)$ & $\varphi\left({ }^{\circ}\right)$ \\
\hline$(5 i)$ & $46.9(1)$ & $52.4(1)$ & 5.5 & $0.580(1)$ & $176.4(1)$ & $280(2)$ \\
$(5 j)$ & $47.4(2)$ & $48.0(3)$ & 0.6 & $0.558(2)$ & $176.0(2)$ & $189(4)$ \\
$(5 k)$ & $40.4(1)$ & $53.0(1)$ & 12.6 & $0.541(1)$ & $171.1(1)$ & $342(1)$ \\
$(5 a)^{a}$ & $47.3(1)$ & $50.8(1)$ & 3.6 & $0.573(1)$ & $178.4(1)$ & $234(4)$ \\
$(5 b)^{a}$ & $48.2(1)$ & $50.3(1)$ & 2.1 & $0.577(1)$ & $177.5(1)$ & $199(2)$ \\
$(4)^{b}$ & $35.9(1)$ & $51.8(2)$ & 15.9 & $0.514(2)$ & $167.5(2)$ & $349(1)$ \\
\hline
\end{tabular}

References: (a) Ślepokura (2008) $\left\{(5 a)\right.$ is (cha) $\left[(\mathrm{MeO})_{2} \mathrm{cDHAP}\right] \cdot 3 \mathrm{H}_{2} \mathrm{O}$ and $(5 b)$ is monoclinic (cha) $\left.\left[(\mathrm{MeO})_{2} \mathrm{cDHAP}\right] \cdot \mathrm{H}_{2} \mathrm{O}\right\} ;$ (b) Ślepokura \& Lis (2004b) [(4) is $\left.(\mathrm{MeO})_{2} \mathrm{cDHAP}(\mathrm{Ph})\right]$.

\section{Compound (5i)}

Crystal data

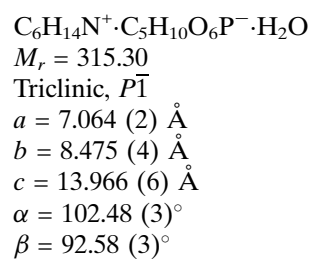

$\gamma=99.96(3)^{\circ}$

$V=801.1(6) \AA^{3}$

$Z=2$

Mo $K \alpha$ radiation

$\mu=0.20 \mathrm{~mm}^{-1}$

$T=100 \mathrm{~K}$

$0.37 \times 0.23 \times 0.04 \mathrm{~mm}$

\section{Data collection}

Kuma KM-4 CCD

$\kappa$-geometry diffractometer with a Sapphire CCD camera

Absorption correction: multi-scan

(CrysAlis RED; Oxford

Refinement

$R\left[F^{2}>2 \sigma\left(F^{2}\right)\right]=0.034$

$w R\left(F^{2}\right)=0.094$

$S=1.03$

4519 reflections

190 parameters

\section{Compound (5j)}

Crystal data

$\mathrm{C}_{6} \mathrm{H}_{14} \mathrm{~N}^{+} \cdot \mathrm{C}_{5} \mathrm{H}_{10} \mathrm{O}_{6} \mathrm{P}^{-}$

$M_{r}=297.28$

Orthorhombic, $P 2_{1} 2_{1} 2_{1}$

$a=6.678$ (2) $\AA$

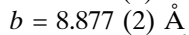

$c=24.930(6) \AA$

\section{Data collection}

Oxford Diffraction Xcalibur PX $\kappa$-geometry diffractometer with an Onyx CCD camera

Absorption correction: analytical (CrysAlis RED; Oxford

Refinement

$R\left[F^{2}>2 \sigma\left(F^{2}\right)\right]=0.037$

$w R\left(F^{2}\right)=0.060$

$S=1.02$

2803 reflections

175 parameters

$\mathrm{H}$-atom parameters constrained

$$
\begin{aligned}
& V=1477.9(7) \AA^{3} \\
& Z=4 \\
& \text { Cu } K \alpha \text { radiation } \\
& \mu=1.86 \mathrm{~mm}^{-1} \\
& T=120 \mathrm{~K} \\
& 0.13 \times 0.08 \times 0.01 \mathrm{~mm}
\end{aligned}
$$

\section{Compound (5k)}

\section{Crystal data}

$\mathrm{C}_{5} \mathrm{H}_{11} \mathrm{O}_{6} \mathrm{P}$

$M_{r}=198.11$

Triclinic, $P \overline{1}$

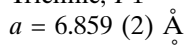

$b=7.114(3) \AA$

$c=8.939(3) \AA$

$\alpha=89.13(3)^{\circ}$

$\beta=76.00(3)^{\circ}$
Diffraction, 2009)

$T_{\min }=0.832, T_{\max }=0.978$ 11210 measured reflections 2803 independent reflections 1876 reflections with $I>2 \sigma(I)$ $R_{\text {int }}=0.062$ 
Table 2

Selected geometric parameters $\left(\AA{ }^{\circ}\right)$ for $(5 i)-(5 k)$.

\begin{tabular}{|c|c|c|c|}
\hline & $(5 i)$ & $(5 j)$ & $(5 k)$ \\
\hline $\mathrm{P} 1-\mathrm{O} 1$ & $1.6061(10)$ & $1.5929(18)$ & $1.5721(10)$ \\
\hline $\mathrm{P} 1-\mathrm{O} 3$ & $1.6004(10)$ & 1.6013 (18) & $1.5614(11)$ \\
\hline $\mathrm{P} 1-\mathrm{O} 4$ & $1.4866(10)$ & $1.4846(18)$ & $1.5453(11)$ \\
\hline $\mathrm{P} 1-\mathrm{O} 5$ & $1.4784(11)$ & $1.4753(18)$ & $1.4727(10)$ \\
\hline $\mathrm{O} 1-\mathrm{C} 1$ & $1.4343(14)$ & $1.445(3)$ & $1.4488(14)$ \\
\hline $\mathrm{O} 21-\mathrm{C} 2$ & $1.4118(13)$ & $1.415(3)$ & $1.4071(14)$ \\
\hline $\mathrm{O} 21-\mathrm{C} 4$ & $1.4328(15)$ & $1.436(4)$ & $1.4304(16)$ \\
\hline $\mathrm{O} 22-\mathrm{C} 2$ & $1.4080(13)$ & $1.417(3)$ & 1.3999 (13) \\
\hline $\mathrm{O} 22-\mathrm{C} 5$ & $1.4229(15)$ & $1.431(3)$ & $1.4319(14)$ \\
\hline $\mathrm{O} 3-\mathrm{C} 3$ & $1.4304(14)$ & $1.425(3)$ & $1.4543(15)$ \\
\hline $\mathrm{C} 1-\mathrm{C} 2$ & $1.5270(15)$ & $1.510(4)$ & $1.5253(16)$ \\
\hline $\mathrm{C} 2-\mathrm{C} 3$ & $1.5297(16)$ & $1.515(4)$ & $1.5267(16)$ \\
\hline $\mathrm{O} 1-\mathrm{P} 1-\mathrm{O} 3$ & $102.13(5)$ & $101.74(10)$ & $105.77(5)$ \\
\hline $\mathrm{O} 1-\mathrm{P} 1-\mathrm{O} 4$ & $109.24(5)$ & $109.49(9)$ & $107.67(6)$ \\
\hline $\mathrm{O} 1-\mathrm{P} 1-\mathrm{O} 5$ & $107.69(5)$ & $109.15(10)$ & $110.23(6)$ \\
\hline $\mathrm{O} 3-\mathrm{P} 1-\mathrm{O} 4$ & $109.74(5)$ & $109.33(10)$ & $105.76(6)$ \\
\hline $\mathrm{O} 3-\mathrm{P} 1-\mathrm{O} 5$ & $106.58(6)$ & $108.30(11)$ & $111.75(6)$ \\
\hline $\mathrm{O} 4-\mathrm{P} 1-\mathrm{O} 5$ & $119.97(5)$ & $117.64(11)$ & $115.13(6)$ \\
\hline $\mathrm{P} 1-\mathrm{O} 1-\mathrm{C} 1$ & $114.57(7)$ & $115.64(17)$ & $116.69(7)$ \\
\hline $\mathrm{C} 2-\mathrm{O} 21-\mathrm{C} 4$ & $114.41(9)$ & $114.8(3)$ & $116.04(9)$ \\
\hline $\mathrm{C} 2-\mathrm{O} 22-\mathrm{C} 5$ & $115.66(9)$ & $115.2(2)$ & $115.71(9)$ \\
\hline $\mathrm{P} 1-\mathrm{O} 3-\mathrm{C} 3$ & $116.69(7)$ & $115.64(17)$ & $118.21(7)$ \\
\hline $\mathrm{O} 1-\mathrm{C} 1-\mathrm{C} 2$ & $109.64(9)$ & $111.5(2)$ & $109.72(9)$ \\
\hline $\mathrm{O} 21-\mathrm{C} 2-\mathrm{O} 22$ & $111.81(9)$ & $111.8(2)$ & $113.39(9)$ \\
\hline $\mathrm{O} 21-\mathrm{C} 2-\mathrm{C} 1$ & $104.21(9)$ & $111.8(2)$ & $102.94(9)$ \\
\hline $\mathrm{O} 22-\mathrm{C} 2-\mathrm{C} 1$ & $113.65(9)$ & $105.7(3)$ & $113.94(9)$ \\
\hline $\mathrm{O} 21-\mathrm{C} 2-\mathrm{C} 3$ & $112.14(9)$ & $103.7(2)$ & $111.50(9)$ \\
\hline $\mathrm{O} 22-\mathrm{C} 2-\mathrm{C} 3$ & $105.01(9)$ & $112.7(2)$ & $104.92(9)$ \\
\hline $\mathrm{C} 1-\mathrm{C} 2-\mathrm{C} 3$ & $110.21(9)$ & $111.3(2)$ & $110.33(10)$ \\
\hline $\mathrm{O} 3-\mathrm{C} 3-\mathrm{C} 2$ & $110.72(9)$ & $112.2(2)$ & $110.28(9)$ \\
\hline $\mathrm{O} 3-\mathrm{P} 1-\mathrm{O} 1-\mathrm{C} 1$ & $55.31(8)$ & $54.88(18)$ & $47.93(9)$ \\
\hline $\mathrm{O} 4-\mathrm{P} 1-\mathrm{O} 1-\mathrm{C} 1$ & $-60.85(8)$ & $-60.73(19)$ & $-64.78(9)$ \\
\hline $\mathrm{O} 5-\mathrm{P} 1-\mathrm{O} 1-\mathrm{C} 1$ & $167.33(7)$ & $169.19(17)$ & $168.89(7)$ \\
\hline $\mathrm{O} 1-\mathrm{P} 1-\mathrm{O} 3-\mathrm{C} 3$ & $-52.80(8)$ & $-54.61(19)$ & $-45.92(9)$ \\
\hline $\mathrm{O} 4-\mathrm{P} 1-\mathrm{O} 3-\mathrm{C} 3$ & $63.00(9)$ & $61.1(2)$ & $68.13(9)$ \\
\hline $\mathrm{O} 5-\mathrm{P} 1-\mathrm{O} 3-\mathrm{C} 3$ & $-165.65(7)$ & $-169.55(18)$ & $-165.89(7)$ \\
\hline $\mathrm{P} 1-\mathrm{O} 1-\mathrm{C} 1-\mathrm{C} 2$ & $-62.20(9)$ & $-58.2(3)$ & $-57.28(11)$ \\
\hline $\mathrm{P} 1-\mathrm{O} 3-\mathrm{C} 3-\mathrm{C} 2$ & $56.68(10)$ & $57.6(3)$ & $53.06(11)$ \\
\hline $\mathrm{C} 4-\mathrm{O} 21-\mathrm{C} 2-\mathrm{O} 22$ & $60.27(12)$ & $-63.4(3)$ & $50.07(12)$ \\
\hline $\mathrm{C} 4-\mathrm{O} 21-\mathrm{C} 2-\mathrm{C} 1$ & $-176.57(8)$ & $54.9(4)$ & $173.64(9)$ \\
\hline $\mathrm{C} 4-\mathrm{O} 21-\mathrm{C} 2-\mathrm{C} 3$ & $-57.38(12)$ & $174.9(3)$ & $-68.09(13)$ \\
\hline $\mathrm{C} 5-\mathrm{O} 22-\mathrm{C} 2-\mathrm{O} 21$ & $67.92(11)$ & $-60.9(3)$ & $65.74(12)$ \\
\hline $\mathrm{C} 5-\mathrm{O} 22-\mathrm{C} 2-\mathrm{C} 1$ & $-49.72(12)$ & $177.2(2)$ & $-51.58(13)$ \\
\hline $\mathrm{C} 5-\mathrm{O} 22-\mathrm{C} 2-\mathrm{C} 3$ & $-170.24(9)$ & $55.4(3)$ & $-172.36(9)$ \\
\hline $\mathrm{O} 1-\mathrm{C} 1-\mathrm{C} 2-\mathrm{O} 21$ & $179.58(7)$ & $168.6(2)$ & $178.45(8)$ \\
\hline $\mathrm{O} 1-\mathrm{C} 1-\mathrm{C} 2-\mathrm{O} 22$ & $-58.46(11)$ & $-69.6(3)$ & $-58.34(12)$ \\
\hline $\mathrm{O} 1-\mathrm{C} 1-\mathrm{C} 2-\mathrm{C} 3$ & $59.08(11)$ & $53.1(3)$ & $59.37(11)$ \\
\hline $\mathrm{O} 21-\mathrm{C} 2-\mathrm{C} 3-\mathrm{O} 3$ & $-171.66(8)$ & $-173.6(2)$ & $-170.68(8)$ \\
\hline $\mathrm{O} 22-\mathrm{C} 2-\mathrm{C} 3-\mathrm{O} 3$ & $66.71(11)$ & $65.3(3)$ & $66.19(11)$ \\
\hline $\mathrm{C} 1-\mathrm{C} 2-\mathrm{C} 3-\mathrm{O} 3$ & $-56.06(11)$ & $-53.2(3)$ & $-56.94(12)$ \\
\hline
\end{tabular}

\section{Data collection}

Kuma KM-4 CCD $\kappa$-geometry diffractometer with a Sapphire CCD camera

Absorption correction: multi-scan (CrysAlis RED; Oxford

\section{Refinement}

$R\left[F^{2}>2 \sigma\left(F^{2}\right)\right]=0.030$

$w R\left(F^{2}\right)=0.086$

$S=1.08$

2274 reflections

$$
\begin{aligned}
& \text { Diffraction, 2009) } \\
& T_{\min }=0.970, T_{\max }=1.000 \\
& 5919 \text { measured reflections } \\
& 2274 \text { independent reflections } \\
& 1985 \text { reflections with } I>2 \sigma(I) \\
& R_{\text {int }}=0.016
\end{aligned}
$$

112 parameters $\Delta \rho_{\max }=0.55{\mathrm{e} \AA^{-3}}^{-3}$

$\Delta \rho_{\min }=-0.25 \mathrm{e}^{-3}$

\begin{tabular}{|c|c|c|c|c|c|}
\hline Compound & $D-\mathrm{H} \cdots A$ & $D-\mathrm{H}$ & $\mathrm{H} \cdots A$ & $D \cdots A$ & $D-\mathrm{H} \cdots A$ \\
\hline \multirow[t]{7}{*}{$(5 i)$} & $\mathrm{N} 1-\mathrm{H} 1 \mathrm{~N} \cdots \mathrm{O} 5$ & 0.91 & 1.87 & $2.758(2)$ & 166 \\
\hline & $\mathrm{N} 1-\mathrm{H} 2 \mathrm{~N} \cdots \mathrm{O} 5^{\mathrm{i}}$ & 0.91 & 1.96 & $2.817(2)$ & 157 \\
\hline & $\mathrm{N} 1-\mathrm{H} 3 \mathrm{~N} \cdots \mathrm{O} 1 W^{\mathrm{ii}}$ & 0.91 & 1.87 & $2.719(2)$ & 154 \\
\hline & $\mathrm{O} 1 W-\mathrm{H} 1 W \cdots \mathrm{O} 4$ & $0.83(2)$ & $1.92(2)$ & $2.749(2)$ & $176(2)$ \\
\hline & $\mathrm{O} 1 W-\mathrm{H} 2 W \cdots \mathrm{O} 4^{\mathrm{iii}}$ & $0.83(2)$ & $1.93(2)$ & $2.758(2)$ & $176(2)$ \\
\hline & $\mathrm{C} 4-\mathrm{H} 4 A \cdots \mathrm{O} 1^{\text {iv }}$ & 0.98 & 2.60 & $3.534(2)$ & 159 \\
\hline & $\mathrm{C} 11-\mathrm{H} 11 \cdots \mathrm{O} 1 W^{\mathrm{iii}}$ & 1.00 & 2.52 & $3.416(2)$ & 149 \\
\hline \multirow[t]{5}{*}{$(5 j)$} & $\mathrm{N} 1-\mathrm{H} 1 \mathrm{~N} \cdots \mathrm{O} 5$ & 0.91 & 1.81 & $2.718(3)$ & 172 \\
\hline & $\mathrm{N} 1-\mathrm{H} 2 \mathrm{~N} \cdots \mathrm{O} 4^{\mathrm{ii}}$ & 0.91 & 1.90 & 2.809 (3) & 174 \\
\hline & $\mathrm{N} 1-\mathrm{H} 3 \mathrm{~N} \cdots \mathrm{O} 4^{\mathrm{v}}$ & 0.91 & 1.90 & $2.799(3)$ & 169 \\
\hline & $\mathrm{C} 3-\mathrm{H} 3 B \cdots \mathrm{O} 22^{\mathrm{vi}}$ & 0.99 & 2.60 & $3.495(3)$ & 150 \\
\hline & $\mathrm{C} 14-\mathrm{H} 14 A \cdots \mathrm{O}^{\mathrm{vii}}$ & 0.99 & 2.50 & $3.396(3)$ & 150 \\
\hline \multirow[t]{4}{*}{$(5 k)$} & $\mathrm{O} 4-\mathrm{H} 4 \cdots \mathrm{O}^{\mathrm{iii}}$ & 0.84 & 1.70 & $2.533(2)$ & 175 \\
\hline & $\mathrm{C} 1-\mathrm{H} 1 A \cdots \mathrm{O} 21^{\mathrm{viii}}$ & 0.99 & 2.57 & $3.544(2)$ & 169 \\
\hline & $\mathrm{C} 3-\mathrm{H} 3 B \cdots \mathrm{O} 22^{\mathrm{ix}}$ & 0.99 & 2.61 & $3.560(2)$ & 161 \\
\hline & $\mathrm{C} 5-\mathrm{H} 5 B \cdots \mathrm{O}^{\mathrm{x}}$ & 0.98 & 2.49 & $3.423(2)$ & 159 \\
\hline
\end{tabular}

$\mathrm{H}$-atom parameters constrained

All $\mathrm{H}$ atoms were found in difference Fourier maps. In the final refinement cycles, water $\mathrm{H}$ atoms in $(5 i)$ were refined with $U_{\text {iso }}(\mathrm{H})=$
Table 3

Hydrogen-bond geometry $\left(\AA,^{\circ}\right)$ for $(5 i)-(5 k)$.

Symmetry codes: (i) $-x,-y,-z+1$; (ii) $x-1, y, z$; (iii) $-x+1,-y+1,-z+1$; (iv) $x+1$, $y, z$; (v) $x-\frac{1}{2},-y+\frac{1}{2},-z+1$; (vi) $-x+1, y+\frac{1}{2},-z+\frac{1}{2}$; (vii) $x, y+1, z$. (viii) $-x+2,-y+2$, $-z+1$; (ix) $-x+2,-y+2,-z$; (x) $-x+2,-y+1,-z$.

$1.5 U_{\text {eq }}(\mathrm{O})$. All remaining $\mathrm{H}$ atoms were treated as riding atoms in geometrically optimized positions, with $\mathrm{C}-\mathrm{H}=0.98-1.00 \AA$ ․ $\mathrm{N}-\mathrm{H}=$ $0.91 \AA$ and $\mathrm{O}-\mathrm{H}=0.84 \AA$, and with $U_{\text {iso }}(\mathrm{H})=1.2 U_{\text {eq }}(\mathrm{C})$ for $\mathrm{CH}$ and $\mathrm{CH}_{2}$, or $1.5 U_{\text {eq }}(\mathrm{C}, \mathrm{N}, \mathrm{O})$ for $\mathrm{CH}_{3}, \mathrm{NH}_{3}$ and $\mathrm{OH}$.

For all compounds, data collection: CrysAlis CCD (Oxford Diffraction, 2009); cell refinement: CrysAlis RED (Oxford Diffraction, 2009); data reduction: CrysAlis RED; program(s) used to solve structure: SHELXS97 (Sheldrick, 2008); program(s) used to refine structure: SHELXL97 (Sheldrick, 2008); molecular graphics: XP (Bruker, 1998); software used to prepare material for publication: SHELXL97 and PLATON (Spek, 2009).

Supplementary data for this paper are available from the IUCr electronic archives (Reference: MX3045). Services for accessing these data are described at the back of the journal.

\section{References}

Allen, F. H. (2002). Acta Cryst. B58, 380-388.

Bernstein, J., Davis, R. E., Shimoni, L. \& Chang, N.-L. (1995). Angew. Chem. Int. Ed. Engl. 34, 1555-1573.

Bruker (1998). XP. Version 5.1. Bruker AXS Inc., Madison, Wisconsin, USA. Cremer, D. \& Pople, J. A. (1975). J. Am. Chem. Soc. 97, 1354-1358.

Flack, H. D. (1983). Acta Cryst. A39, 876-881.

Gerlt, J. A., Chodosh, D. F., Drews, R. E. \& Adams, R. D. (1980). J. Org. Chem. 45, $1282-1286$.

Goswami, S. \& Adak, A. K. (2002). Tetrahedron Lett. 43, 503-505.

Johnson, O., Jones, D. W. \& Edmundson, R. S. (1989). Acta Cryst. C45, 142 145.

Oxford Diffraction (2009). CrysAlis CCD and CrysAlis RED, in Xcalibur PX and Kuma KM-4 CCD software. Versions 1.171.33.42. Oxford Diffraction Ltd, Yarnton, Oxfordshire, England.

Samas, B., Groendyke, T., Blackburn, A. C. \& Godrej, D. B. (2007). Acta Cryst. E63, o1276-o1278.

Sheldrick, G. M. (2008). Acta Cryst. A64, 112-122.

Shinitzky, M., Haimovitz, R., Nemas, M., Cahana, N., Mamillapalli, R. \& Seger, R. (2000). Eur. J. Biochem. 267, 2547-2554.

Ślepokura, K. (2008). Carbohydr. Res. 343, 113-131.

Ślepokura, K. \& Lis, T. (2004a). Carbohydr. Res. 339, 1995-2007.

Ślepokura, K. \& Lis, T. (2004b). Acta Cryst. C60, o315-o317.

Ślepokura, K. \& Lis, T. (2006). Carbohydr. Res. 341, 507-524.

Ślepokura, K. \& Lis, T. (2010). Carbohydr. Res. 345, 512-529.

Spek, A. L. (2009). Acta Cryst. D65, 148-155. 